\title{
Transparent Tubular Retractor in Cranial Surgery: A Retrospective Analysis
}

\author{
Sundaravadhanan Shashivadhanan ${ }^{1}$ \\ ${ }^{1}$ Department of Neurosurgery, Command Hospital Air Force, \\ Bengaluru, Karnataka, India
}

Indian J Neurosurg 2019;8:13-16

\begin{abstract}
Address for correspondence Sundaravadhanan Shashivadhanan, MS, DNB (Gen Surg), MCh, DNB (Neurosurg), Department of Neurosurgery, Command Hospital Air Force, Bengaluru 560007, Karnataka, India (e-mail: drshashivadhanan@gmail.com).
\end{abstract}

\begin{abstract}
Keywords

- transparent tubular retractor

- retraction injury

- minimally invasive surgery

Introduction The fourth Industrial Revolution has touched nearly all aspects of neurosurgery and the newer tubular retractor systems are a testimony to this fact. They aid in providing better visualization with minimal damage to those neural structures, which happen to be innocent bystanders overlying the path of deep-seated lesions. In addition to providing better patient outcomes they are surgeon friendly with their ergonomic design and improved stability, thereby causing minimal fatigue, and aid in procedures requiring precision and perseverance. A retrospective study conducted at a single institute analyzed the efficacy of transparent tubular retractors during cranial surgery for deep-seated lesions.

Materials and Methods This retrospective study was conducted between April 2015 and July 2018 in a single institute wherein 22 patents with various deep-seated intracranial lesions were operated using the transparent tubular retractor, View Site Brain Access System (VBAS, Vycor Medical Inc.).

Observation Of the 22 cases, $45 \%$ were of spontaneous intracerebral hemorrhage; $27 \%$ were high-grade gliomas; and the rest were colloid cyst, cystic tumors, and metastatic tumors in equal proportion. Total tumor excision was achieved in $27 \%$, while $90 \%$ excision was achieved in $45 \%$ cases. The overall complication rate was $13 \%$.

Conclusion The transparent tubular retractors contribute to minimal invasiveness by causing uniform distribution of retraction pressure and minimal disruption of fiber tracts. Their use has a definite role in improving surgical outcomes for deep-seated intracranial lesions.
\end{abstract}

\section{Introduction}

As neurosurgeons began venturing deep beneath the dura, there came a need for retractors. Since 19th century retractors have been used to provide better visualization and more angulations without compromising on stability and causing minimal brain retraction injury. Our understanding on brain tissue behavior and response to retraction has improved in the past decade. This has led to an era of minimally invasive retraction.

Minimal retraction is now an integral part of minimally invasive surgery philosophy. It means utilizing natural planes and corridors for dissection, and application of minimal retraction only when necessary. It also entails causing minimal disruption of tracts or fiber while approaching deep-seated lesions. At the end of surgery it leaves behind a negligible neurosurgical footprint. ${ }^{1}$

The fourth Industrial Revolution has touched nearly all aspects of neurosurgery and the newer tubular retractor systems are a testimony to this fact. They aid in providing better visualization with minimal damage to the neural structures, which happen to be innocent bystanders overlying the path for deep-seated lesions. In addition to providing better patient outcomes they are neurosurgeon friendly with their ergonomic
DOI https://doi.org/ $10.1055 / \mathrm{s}-0039-1698844$ ISSN 2277-954X.
License terms

()(1) $\odot \circledast$ 
design and improved stability. They minimize fatigue and aid in procedures requiring precision and perseverance.

Retractor pressure due to traditional multiple retraction blades occludes blood vessels, reduces tissue perfusion, and creates local ischemia leading to infarction. Animal studies have proven that a low external pressure of $25 \mathrm{~mm} \mathrm{Hg}$ may lead to electroencephalographic changes and blood-brain barrier disruption. ${ }^{2-4}$

Literature shows that at least $10 \%$ of skull base surgeries and $5 \%$ of aneurysm surgeries are complicated by brain infarction or contusion resulting from retraction. ${ }^{5}$

The newer tubular retractor systems work toward minimizing these side effects. The tubular retraction system reduces pressure on the retracted tissue by evenly distributing pressure over the entire surface of the cylinder. This reduces the incidence of trauma and its associated complications. ${ }^{6,7}$

Tubular retractors were introduced in cranial surgery since 2010. There is a strong body of literature which supports their safety and efficacy. ${ }^{8-10}$ Our present study was done to evaluate the safety and efficacy of the transparent tubular retractor and critically compare its outcomes with the conventional retractors blades which have been the workhorse for any surgical procedure involving excision of deep-seated lesions within the brain.

\section{Materials and Methods}

This retrospective study was conducted in a single institution between April 2015 and July 2018. In this study, 22 patients with deep-seated subcortical supratentorial lesions were subjected to excision aided by use of transparent tubular retractor, View Site Brain Access System (VBAS, Vycor Medical Inc.) ( - Fig. 1). The ease of use, extent of resection, and complications were analyzed and conclusions were drawn.

The outcomes were analyzed and conclusions were drawn. The postoperative outcomes were further compared with historical control group which shared a similar clinicoradiological profile, wherein, the conventional retractor blades were used.

\section{Retraction Technique}

Based on anatomical landmarks and neuroimaging eloquent areas are marked and vascular areas are noted. A 3 to $4 \mathrm{~cm}^{2}$ area of brain's cortical surface is exposed following craniotomy and durotomy. Centering on the trajectory entry point, trans-sulcal dissection is done. If that is not possible then a linear transcortical pial defect is created and superficial cortex is incised. Depending on the depth of the lesion an appropriate retractor is chosen and gently inserted along with a transparent obturator perpendicular to brain surface (-Figs. 2,3). Once the tumor or hematoma is visualized, the obturator is withdrawn. The tumor can be seen bulging within the retractor. At this stage the retractor is ether fixed to the table or the assistant has to hold it maintaining a constant pressure so as to prevent the retractor from being pushed out by the surrounding brain parenchyma (-Fig. 4). Depending on the consistency and extent of tumor infiltration, microinstruments are used to debulk/excise the tumor. To improve the visual field, the retractor can be gently angled. Once satisfactory excision and hemostasis is achieved,

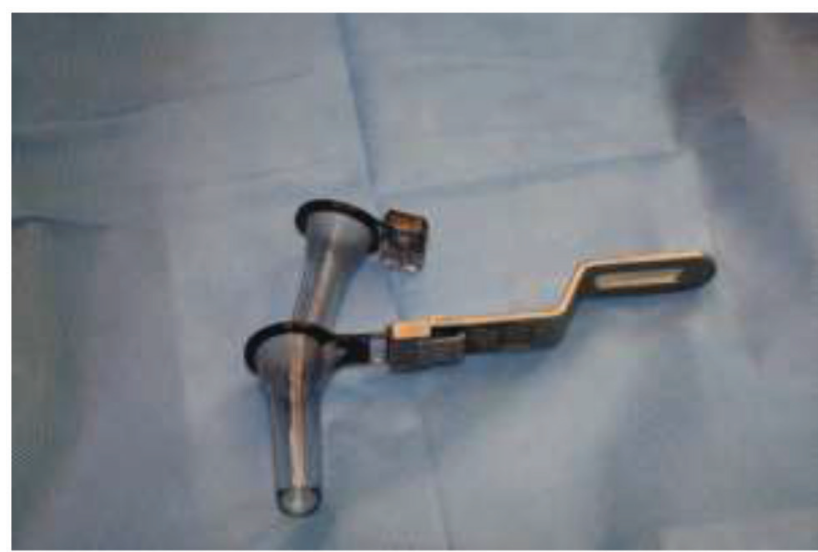

Fig. 1 The transparent tubular retractor with an outer cannula and an inner obturator which is transparent.

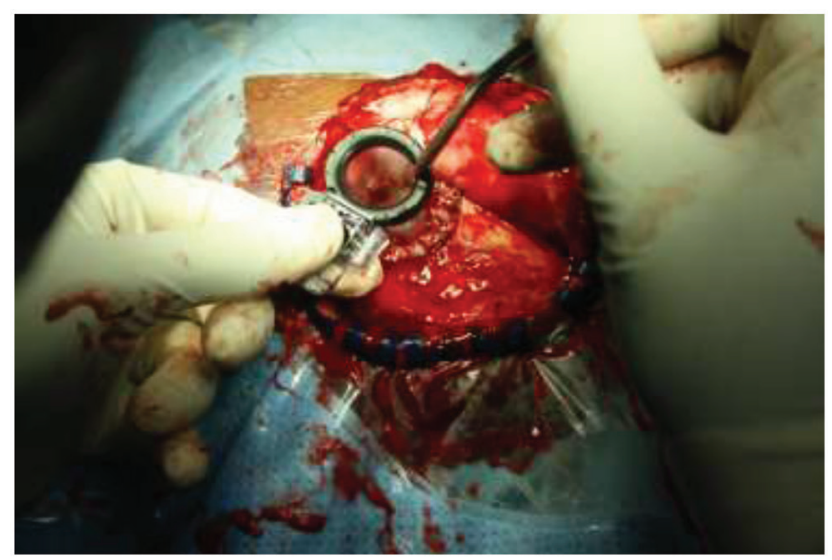

Fig. 2 Insertion of the tubular retractor in a case of spontaneous intracerebral hemorrhage.

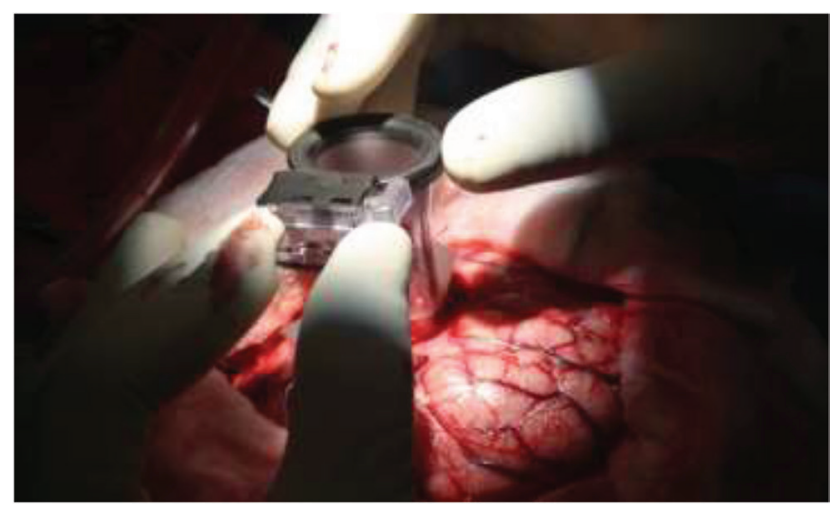

Fig. 3 Tubular retractor placement in a pediatric cystic tumor.

the same can be confirmed using copious saline irrigation into the cavity. Once satisfied the retractor is gently withdrawn ensuring hemostasis till the retractor leaves the cortical surface. Watertight dural closure is done before repositioning and fixing the bone flap ( - Tables 1 and $\mathbf{2}$ ).

\section{Observation}

Of the total 22 cases operated, 10 (45\%) were those with spontaneous intracerebral hematoma causing life-threatening mass effect. They required larger cortisectomy 
defects and relatively larger diameter tubular retractors. Vigorous removal of adherent clots was avoided as this resulted in fresh hemorrhage, controlling which required angled cautery tips and flowable hemostats. Size of craniectomy defect was determined by the extent of angulation required for complete excision of lesion. The retractors were fixed whenever both hands were required for dissection and excision.

Small lesions having a safe and straight trajectory were technically less demanding.

For colloid cysts, metastatic tumors, and cystic tumors gross total resection could be achieved. For high-grade gliomas and intracerebral hemorrhage the excision was satisfactory. Extent of excision was confirmed sing CT/MRI scan on case to case basis within the first 24 hours following surgery.

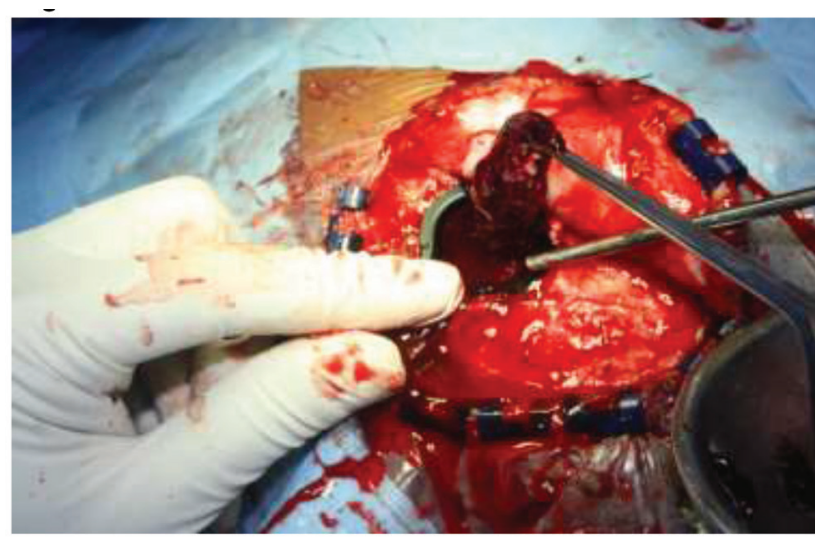

Fig. 4 Clot removal using the transparent tubular retractor system.
In all cases there was a small cortical incision footprint following removal of the retractor system with minimal effects of retraction-induced cortical ischemia; the overall complication (not associated with retraction) was $13 \%$.

Other than the standard instruments used for brain surgeries there was requirement of angled bipolar cautery and flowable hemostats. Also, there is requirement of good lighting system which needs frequent adjustment depending on the dynamic of depth and angulation. It is preferable to use a head-mounted light source. Neuronavigation helps in marking a minimally short and safe trajectory.

On comparison with historical controls sharing similar clinical profile it was observed that $8 \%$ of cases operated using blade retractors developed retraction site infarction (evident in the postoperative imaging). With use of tubular retractor there was not a single case of retractor-induced infarction. There was also reduced requirement of steroids and cerebral decongestants in the postoperative period in cases where tubular retractors were used. The ease of surgery and time taken was comparable in both groups.

\section{Result}

Our study has shown that use of transparent tubular retractor system is very useful in deep-seated subcortical lesions. They are a useful adjunct in minimally invasive cranial surgeries and can be used in elective and emergency procedures. The technique is not very demanding. Preoperative planning of the retractor insertion path and its relation to the complete tumor are important factors to be considered before undertaking its use.

Table 1 The pathological type of lesion and extent of excision

\begin{tabular}{|l|l|l|l|}
\hline Lesion type & Percentage (total 22 cases) & Percentage of excision & Postoperative complication \\
\hline Intracerbral hemorrhage & $10 / 22(45 \%)$ & $90 \%$ & $2 / 22(9 \%)$ \\
\hline Colloid cyst & $2 / 22(9 \%)$ & $100 \%$ & $1 / 22(4 \%)$ \\
\hline High-grade glioma & $6 / 22(27 \%)$ & $60 \%$ & Nil \\
\hline Cystic tumors & $2 / 22(9 \%)$ & $100 \%$ & Nil \\
\hline Metastasis & $2 / 22(9 \%)$ & $100 \%$ & Nil \\
\hline
\end{tabular}

Table 2 The intraoperative features

\begin{tabular}{|l|l|l|l|}
\hline Lesion type & Size of craniotomy defect & Approach & Remarks \\
\hline Intracerebral hemorrhage & $4 \times 4 \mathrm{~cm}$ & $\begin{array}{l}\text { Transcortical after } \\
\text { cauterizing pia mater }\end{array}$ & $\begin{array}{l}\text { Bleeding resulting from removal of } \\
\text { adherent clots at the crevices were } \\
\text { difficult to visualize and cauterize }\end{array}$ \\
\hline Colloid cyst & $4 \times 4 \mathrm{~cm}$ & $\begin{array}{l}\text { Trans-sulcal } \\
\text { tion of cyst wall challenging }\end{array}$ \\
\hline $\begin{array}{l}\text { High-grade glioma crossing } \\
\text { midline }\end{array}$ & $3 \times 3 \mathrm{~cm}$ & Trans-sulcal & $\begin{array}{l}\text { More appropriate for debulking and } \\
\text { getting frozen section }\end{array}$ \\
\hline $\begin{array}{l}\text { Cystic tumor } \\
\text { Metastatic }\end{array}$ & $3 \times 3 \mathrm{~cm}$ & $\begin{array}{l}\text { Trans-sulcal } \\
\text { component }\end{array}$ \\
\hline & $3 \times 3 \mathrm{~cm}$ & $\begin{array}{l}\text { Wrans-sulcal } \\
\text { retractors premed at the solid } \\
\text { used for deep-seated lesions to plan } \\
\text { trajectory }\end{array}$ \\
\hline
\end{tabular}




\section{Discussion}

As in routine cranial surgeries, intraoperative methods of measuring retraction pressure, cerebral blood flow, and electroencephalography are not used. As a result the surgeon remains unaware of the effects of retraction. Retraction-induced infarction contributes to neurologic injury and poor operative outcomes in 5 and 10\% of operated cases of aneurysm and skull base surgeries, respectively. Animal experiments have shown that a pressure of $30 \mathrm{~mm} \mathrm{Hg}$ for 30 minutes reduces cerebral blood flow in tissue opposed to the retractor, resulting in local infarction. ${ }^{11,12}$ Intraoperative hypotension causes further damage due to reduction in perfusion pressure. Tubular retractor systems have attempted to minimize retraction pressure and thus local brain tissue injury when resecting deep-seated lesions and traversing white matter tracts. Kelly et al first described the use of tubular system for resection of lesions within brain parenchyma. ${ }^{13}$

Tubular retractors statistically insignificantly increase average Fluid Attenuated Inversion Recovery (FLAIR) signal intensity volume, although it does increase DWI signal intensity volume in a significant manner. ${ }^{10,14}$ Tubular retractor systems tend to divide and preserve deep white matter, rather than transecting them. Use of blunt-tip passing instrument and progressive dilation technique adds to further protection. ${ }^{2}$ Published data exists in which tubular retractor system was used to excise diverse pathologies. This included neoplastic, cystic, infectious, vascular, and hemorrhagic lesion resections. The overall complication rate resulting from them was 9.1\%. Our data shows that tubular systems have been used successfully in treating ruptured periventricular aneurysm, ${ }^{15}$ intracerebral hemorrhage, ${ }^{16}$ cavernous malformations, ${ }^{17}$ and also in removal of intracranial shrapnel resulting from combat trauma. ${ }^{18} \mathrm{~A}$ multicenter study conducted recently found that trans-sulcal hematoma evacuation using transparent tubular retractor provided a safe approach in patients with intracerebral hemorrhage and also ensured high rates of clot evacuation and postoperative functional independence. ${ }^{19}$

\section{Conclusion}

Our study and the current trend in literature predict that tubular transparent retractors provide a definite advantage during surgery for deep-seated intracranial lesions and are here to stay.

They contribute to minimal invasiveness by causing uniform distribution of retraction pressure and also cause minimal disruption of fiber tracts. Their use has a definite role in improving surgical outcomes. The outcome for any cranial procedure can be further enhanced by preoperative planning which can incorporate Diffusion Tensor Imaging (DTI) imaging and neuronavigation. The future is going to see many more innovative add-ons to the existing system making it an indispensable part of a neurosurgeon's armamentarium.

\section{Conflicts of Interest}

None.

\section{References}

1 Assina R, Rubino S, Sarria CE, Gandhi CD, Prestigiacomo CJ. The history of brain retractors throughout the development of neurological surgery. Neurosurgery Focus 2014;36(4):E8

2 Greenfield JP, Cobb WS, Tsouris AJ, Schwartz TH. Stereotactic minimally invasive tubular retractor system for deep brain lesions. Neurosurgery 2008;63(4, Suppl 2):334-339, discussion 339-340

3 Donaghy RM, Numoto M, Wallman LJ, Flanagan ME. Pressure measurement beneath retractors for protection of delicate tissues. Am J Surg 1972;123(4):429-431

4 Bennett MH, Albin MS, Bunegin L, Dujovny M, Hellstrom H, Jannetta PJ. Evoked potential changes during brain retraction in dogs. Stroke 1977;8(4):487-492

5 Andrews RJ, Bringas JR. A review of brain retraction and recommendations for minimizing intraoperative brain injury. Neurosurgery 1993;33(6):1052-1063

6 Kelly PJ, Goerss SJ, Kall BA. The stereotaxic retractor in computer-assisted stereotaxic microsurgery. Technical note. J Neurosurg 1988;69(2):301-306

7 Harris AE, Hadjipanayis CG, Lunsford LD, Lunsford AK, Kassam AB. Microsurgical removal of intraventricular lesions using endoscopic visualization and stereotactic guidance. Neurosurgery 2005;56(1):125-132

8 Ratre S, Yadav YR, Parihar VS, Kher Y. Microendoscopic removal of deep-seated brain tumors using tubular retraction system. J Neurol Surg A Cent Eur Neurosurg 2016;77(4):312-320

9 Eliyas JK, Glynn R, Kulwin CG, et al. Minimally invasive transsulcal resection of intraventricular and periventricular lesions through a tubular retractor system: multicentric experience and results. World Neurosurg 2016;90:556-564

10 Bander ED, Jones SH, Kovanlikaya I, Schwartz TH. Utility of tubular retractors to minimize surgical brain injury in the removal of deep intraparenchymal lesions: a quantitative analysis of FLAIR hyperintensity and apparent diffusion coefficient maps. J Neurosurg 2016;124(4):1053-1060

11 Rosenørn J, Diemer NH. Reduction of regional cerebral blood flow during brain retraction pressure in the rat. J Neurosurg 1982;56(6):826-829

12 Rosenørn J, Diemer N. The risk of cerebral damage during graded brain retractor pressure in the rat. J Neurosurg 1985;63(4):608-611

13 Kelly PJ, Kall BA, Goerss SJ. Computer-interactive stereotactic resection of deep-seated and centrally located intraaxial brain lesions. Appl Neurophysiol 1987;50(1-6):107-113

14 Greenfield JP, Cobb WS, Tsouris AJ, Schwartz TH. Stereotactic minimally invasive tubular retractor system for deep brain lesions. Neurosurgery 2008;63(ONS Supplement 4):ONS334-ONS340

15 Chen CJ, Caruso J, Starke RM, et al. Endoport-assisted microsurgical treatment of a ruptured periventricular aneurysm. Case Rep Neurol Med 2016;2016:8654262

16 Ding D, Przybylowski CJ, Starke RM, et al. A minimally invasive anterior skull base approach for evacuation of a basal ganglia hemorrhage. J Clin Neurosci 2015;22(11):1816-1819

17 Ding D, Starke RM, Crowley RW, Liu KC. Endoport-assisted microsurgical resection of cerebral cavernous malformations. J Clin Neurosci 2015;22(6):1025-1029

18 Rymarczuk GN, Davidson L, Severson MA, Armonda RA. Use of a minimally invasive retractor system for retrieval of intracranial fragments in wartime trauma. World Neurosurg 2015;84(4):1055-1061

19 Labib MA, Shah M, Kassam AB, et al. The safety and feasibility of image-guided brain path-mediated trans sulcal hematoma evacuation: a multicenter study. Neurosurgery 2017;80(4):515-524 